\title{
Macrochanneled Tetragonal Zirconia Polycrystals Coated by a Calcium Phosphate Layer
}

\author{
Young-Hag Koh, ${ }^{*},+\ddagger$ Hae-Won Kim, ${ }^{*}$ and Hyoun-Ee Kim* \\ School of Materials Science and Engineering, Seoul National University, Seoul, 151-742, Korea
}

John W. Halloran*

Materials Science and Engineering Department, University of Michigan, Ann Arbor, Michigan 48109-2136

\begin{abstract}
A coextrusion process was used to fabricate three-directionally macrochanneled tetragonal zirconia polycrystals (TZP) with a calcium phosphate coating layer. The three-directionally connected structure was built by a unique alignment and a lamination of the TZP surrounded by calcium phosphate and carbon black filaments. After a thermal treatment (binder burnout and sintering), a 52 vol\% array of $290 \mu \mathrm{m}$, threedirectionally connected macrochannels, which were clad on the inside with bioactive calcium phosphate, had formed on the sintered TZP body. For a comparison, porous calcium phosphate with a similar structure was also fabricated. The compressive strength $(96 \mathrm{MPa})$ of the three-directionally macrochanneled TZP with a bioactive calcium phosphate layer was much higher than that (24 MPa) of the three-directionally macrochanneled calcium phosphate.
\end{abstract}

\section{Introduction}

$\mathrm{P}$ OROus calcium phosphate materials have received a lot of attention for use as bone graft materials because of their excellent resorbable and osteoconductive nature ${ }^{1-4}$ due to the crystallographic and chemical similarity with various calcified tissues in vertebrates. ${ }^{5-8}$ Several manufacturing techniques for making these porous bioceramics, such as the hydrothermal exchange process, ${ }^{9}$ and for embedding organic particles in the HA powder have been developed. ${ }^{10-12}$ However, both conventional methods offer both limited control on the pore structure that is critical for its osteoconduction behavior and relatively low compressive strength. ${ }^{13-15}$

Recently, a new fabrication technique for porous bioceramics was developed to improve the control of the pore geometry. ${ }^{16}$ This porous body showed a uniform array of macrochannels on the sintered calcium phosphate body. Furthermore, the compressive strength was enhanced using tetragonal zirconia polycrystal (TZP) bioceramic as a strong body, while its bioinert surface was coated with bioactive calcium phosphate. ${ }^{17}$ However, these porous bodies offered no interconnection between the macrochannels.

Therefore, in this paper, three-directionally macrochanneled TZP, which was coated by a bioactive calcium phosphate layer, was fabricated to enhance the osteoconductivity while maintaining

G. S. Fischman—contributing editor \footnotetext{
Manuscript No. 186439. Received February 10, 2003; approved July 25, 2003.
This research was supported by a grant from the Center for Advanced Materials This research was supported by a grant from the Center for Advanced Materials
Processing (CAMP) of the 21 st Century Frontier R\&D Program funded by the Ministry of Science and Technology, Republic of Korea.

${ }^{\star}$ Member, American Ceramic Society.

Present address: Materials Science and Engineering Department, University of Michigan, Ann Arbor, Michigan 48109-2136.

*Author to whom correspondence should be addressed. e-mail: younghag@engin. umich.edu.
}

the high compressive strength. For comparison, a threedirectionally macrochanneled calcium phosphate was also fabricated. The sintered samples were analyzed by X-ray diffraction (XRD), optical microscopy, scanning electron microscopy (SEM), and electron dispersive spectroscopy (EDS) analysis. The compressive strengths were also measured.

\section{Experimental Procedure}

Commercially available tetragonal zirconia polycrystals (TZ3Y; Tosoh Co., Tokyo, Japan) and calcium phosphate (SigmaAldrich Co., Milwaukee, WI) powder were used as the ceramics. Carbon black powder (Cabot Black Pearls BP-120; Cabot Corp., Boston, MA) was used as a fugitive material, which could be removed after thermal treatment. The calcium phosphate powder was calcined at $900^{\circ} \mathrm{C}$ for $1 \mathrm{~h}$ in air to improve the powder characteristics, as previously reported. ${ }^{16}$ The ceramic (or fugitive) powders were mixed with ethylene ethyl acrylate (EEA 6182; Union Carbide, Danbury, CT) resin at $105^{\circ} \mathrm{C}$ in a heated shear mixer. Processing aids were also added to ensure a consistent apparent viscosity value $(\sim 3000 \mathrm{~Pa} \cdot \mathrm{s})$. The details are described elsewhere. ${ }^{16}$

Once compounded, each thermoplastic compound was molded using either a 22-mm cylindrical mold or a half-piped mold. The initial feed rod of the TZP/calcium phosphate was composed of two materials; that is, a 20 -mm cylindrical TZP core was surrounded by calcium phosphate (shell) with a thickness of $1 \mathrm{~mm}$ (Fig. 1(A)). Similarly, an initial feed rod of carbon black was made with a 22-mm cylindrical mold. The initial feed rods were coextruded using a $300-\mu \mathrm{m}$ orifice at $120^{\circ} \mathrm{C}$ with a crosshead speed of $3 \mathrm{~mm} / \mathrm{min}$ (Fig. 1(B)). This produced continuous and flexible filaments with the same cross sections to the initial feed rods. Two types of filaments (TZP/calcium phosphate and carbon black) were set out alternately using a six-axis mandrel, making $\mathrm{TZP} /$ calcium phosphate filaments neighbored by carbon black filaments (Fig. 1(C)). An adhesive spray was applied to the sheets to connect the filaments. The sheet was cut and biaxially stacked into a 38-mm $\times 38-\mathrm{mm}$ square mold (Fig. 1(D)) and then warm-pressed at $140^{\circ} \mathrm{C}$ with $10 \mathrm{MPa}$, forming a three-directionally connected structure (Fig. 1(E)).

Binder burnout was completed in an alumina tube furnace with a slow heating rate up to $700^{\circ} \mathrm{C}$ in flowing air to avoid the formation of defects in the green body, such as bloating and cracking. After binder burnout, the three-directionally macrochanneled TZP and calcium phosphate billets were sintered at $1500^{\circ}$ and $1350^{\circ} \mathrm{C}$ for $1 \mathrm{~h}$ in air, respectively. The sintered bodies were analyzed by several techniques, such as XRD, optical microscopy, SEM, and EDS. In addition, the compressive strengths were measured for the samples with dimensions of $5 \mathrm{~mm} \times 5 \mathrm{~mm} \times 5$ $\mathrm{mm}$. 
(A)

(B)

(C)

(D)
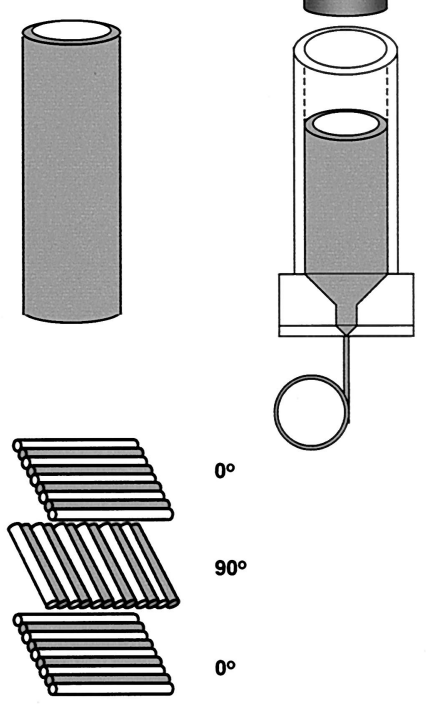

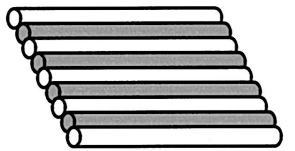

(E)

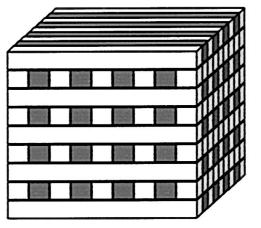

Fig. 1. Schematic illustrations showing the processing route used to fabricate the three-directionally macrochanneled TZP by coextrusion: (A) form the initial feed rod, (B) coextrude the feed rod into the filament, (C) align the filaments alternatively to form a sheet, (D) laminate the sheets to form a solid billet, and (E) remove the polymer binder and consolidate by pyrolysis.

\section{Results and Discussion}

The design of the three-directionally macrochanneled TZP is shown in Fig. 2. The TZP bioceramic was used for the body, which retained the applied stress, while the TZP surface was coated with calcium phosphate to ensure an active osteoconductive behavior. That is, the calcium phosphate layer can be gradually replaced by natural bone, enhancing the interfacial bonding between the implant and natural bone.

A cross-sectional view of a filament of the TZP/calcium phosphate, made by coextrusion, is shown in Fig. 3(A). As expected, the filament shows the same design as the initial feed rod; i.e., a $16-\mu \mathrm{m}$ calcium phosphate layer continuously and uniformly surrounded the TZP core. Furthermore, neither a gap nor overlapping was observed in the unidirectionally aligned filament sheet (Fig. 3(B)). Each sheet was biaxially stacked to build the three-directionally connected structure. Note, the TZP surrounded by calcium phosphate and carbon black appear in the bright and dark contrasts, respectively

The optical photographs of the top view and side view of the sintered three-directionally macrochanneled TZP coated by calcium phosphate are shown in Figs. 4(A) and (B). The body consisted of a 48 vol\% TZP coated by calcium phosphate and a 52 vol\% macrochannel in a uniform array of $290 \mu \mathrm{m}$ (see Table I). Correspondingly, 48 vol\% macrochannels, $278 \mu \mathrm{m}$ in size, were formed in the sintered calcium phosphate body.

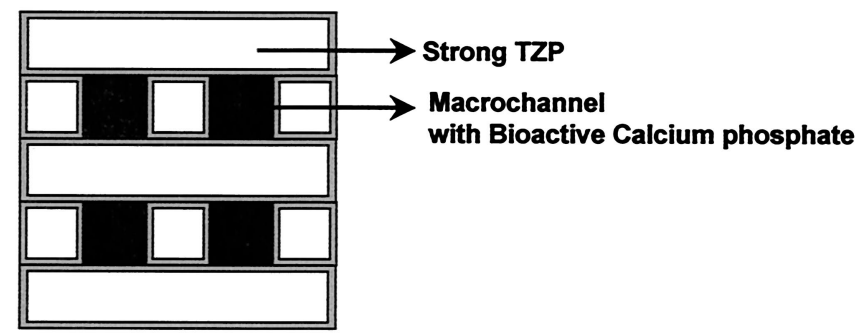

Fig. 2. Schematic design of three-directionally macrochanneled TZP coated with a bioactive calcium phosphate layer.
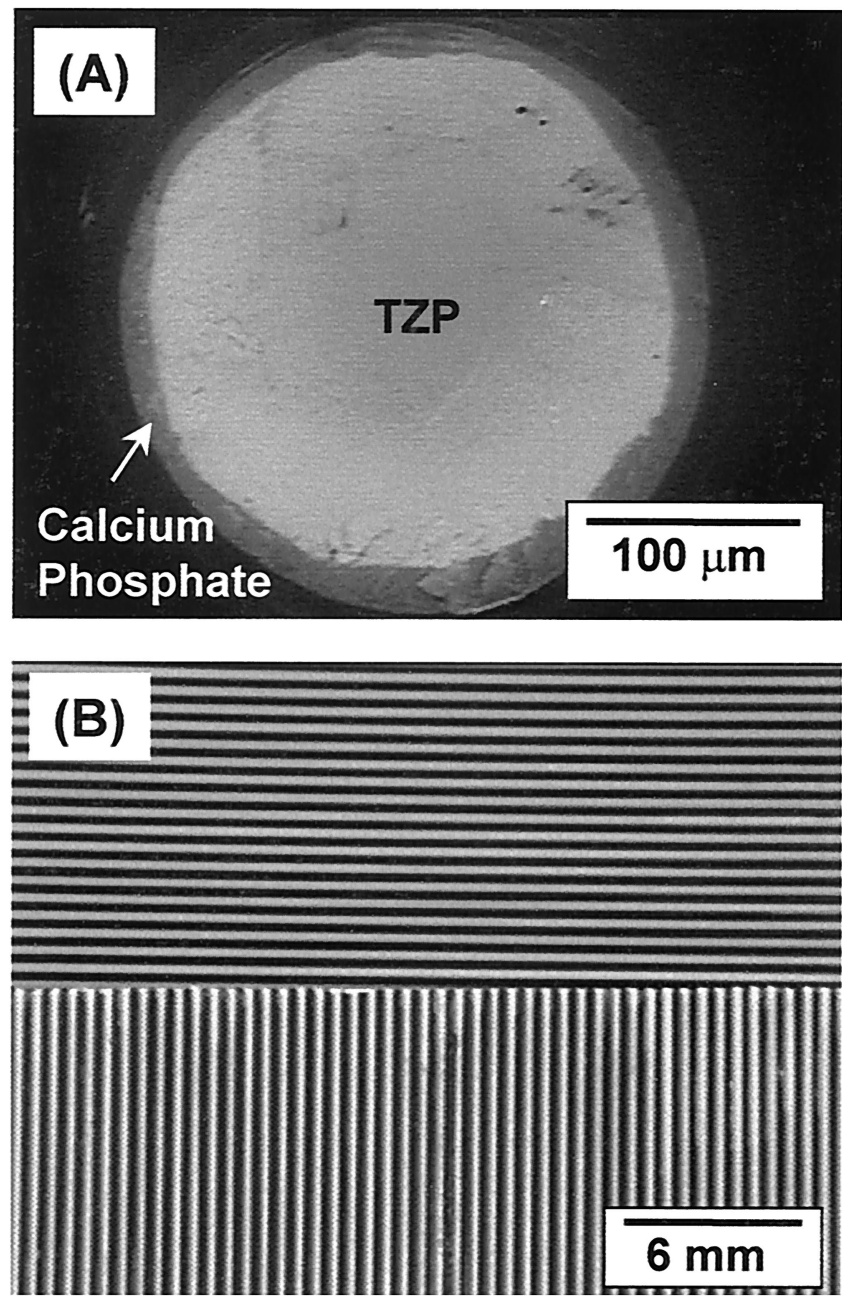

Fig. 3. Optical photograph of (A) cross-sectional view of the TZP/ calcium phosphate filament and (B) the biaxially stacked filament sheet.

Compared with the conventional methods for manufacturing a porous body, the pore structure was accurately controlled. In other words, the porous bodies fabricated by conventional methods had a random pore distribution with a large range of pore size. However, the macrochannel made by coextrusion is almost straight with an extremely narrow size distribution because this macrochannel was formed by removing the carbon black filament after thermal treatment. Moreover, the interconnection size is the same as the macrochannel size, which is important for osteoconductive behavior.

The bioactive calcium phosphate coating layers are shown in Fig. 5. The interfaces between the TZP and calcium phosphate, indicated by the arrows, showed no cracking (Fig. 5(A)). With higher magnification, good interfacial bonding was observed, as shown in Fig. 5(B). The macrochannel was clad on the inside with a bioactive calcium phosphate layer. Considering the thermal stress on cooling, a tensile stress developed on the calcium phosphate layer. However, no cracks were observed at the interface between the TZP and calcium phosphate layer. This good adhesion instead of cracking might be the result of a release of thermal stress by the pores on the sintered calcium phosphate layer.

When calcium phosphate, mostly composed of a crystalline HA $\left(\mathrm{Ca}_{10}\left(\mathrm{PO}_{4}\right)_{6}(\mathrm{OH})_{2}\right)$ phase, is sintered at high temperatures, some parts of the HA phase are converted to a crystalline TCP $\left(\mathrm{Ca}_{3}\left(\mathrm{PO}_{4}\right)_{2}\right)$ phase, leaving pores on the sintered body, according to the following equation: ${ }^{5}$

$$
\mathrm{Ca}_{10}\left(\mathrm{PO}_{4}\right)_{6}(\mathrm{OH})_{2}(s)=3 \mathrm{Ca}_{3}\left(\mathrm{PO}_{4}\right)_{2}(s)+\mathrm{CaO}(s)+\mathrm{H}_{2} \mathrm{O}(g)
$$



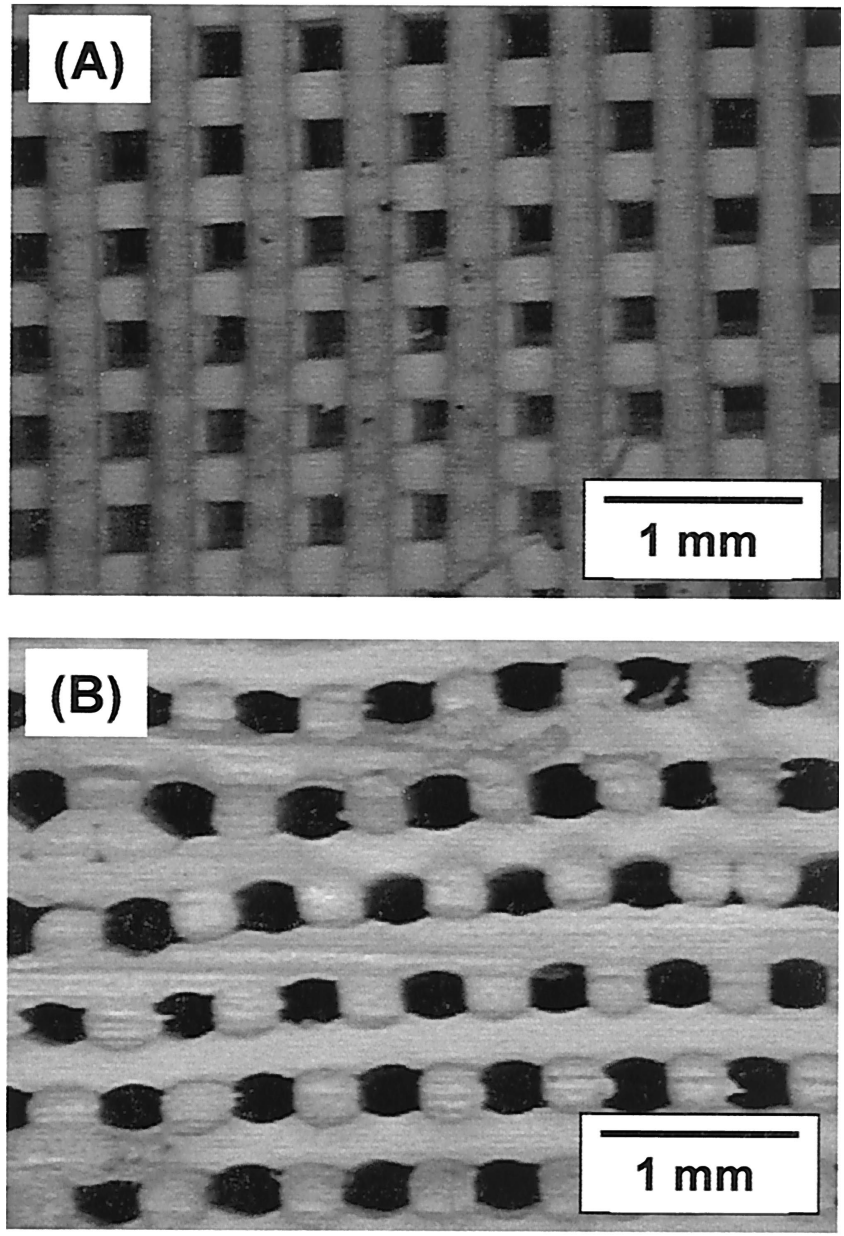

Fig. 4. Optical photographs of (A) top view and (B) side view of three-directionally macrochanneled TZP sintered at $1500^{\circ} \mathrm{C}$ for $1 \mathrm{~h}$.

Furthermore, the HA phase forms the TCP phase with excess zirconia as $\mathrm{CaO}$ enters the partially stabilized zirconia. ${ }^{18}$ The reaction between zirconia and $\mathrm{HA}$ at the interface during sintering might also release the thermal stress. However, XRD showed no evidence of cubic zirconia formation, suggesting that there was a negligible amount of solid solution between $\mathrm{CaO}$ and $\mathrm{ZrO}_{2}$ to be detected.

As expected, the compressive strength $(96 \pm 11 \mathrm{MPa})$ of the three-directionally macrochanneled TZP was almost four times larger $(24 \pm 5 \mathrm{MPa})$ than that of the three-directionally macrochanneled HA, as described in Table I. The remarkable improvement in compressive strength was due to the strong TZP body, which could retain a higher applied compressive stress. Furthermore, its active osteoconductive behavior is expected because its bioinert surface is coated by a bioactive calcium phosphate layer, forming a direct bonding by being replaced by natural bone.

Table I. Summarized Properties of the Three-Directionally Macrochannelled TZP and Three-Directionally Macrochannelled Calcium Phosphate

\begin{tabular}{cccc}
\hline Samples & $\begin{array}{c}\text { Macrochannel } \\
\text { fraction }(\mathrm{vol} \%)\end{array}$ & $\begin{array}{c}\text { Macrochannel } \\
\text { size }(\mu \mathrm{m})\end{array}$ & $\begin{array}{c}\text { Compressive } \\
\text { strength (MPa) }\end{array}$ \\
\hline $\begin{array}{c}\text { Three-directionally } \\
\text { macrochannelled TZP }\end{array}$ & 52 & $290 \pm 17$ & $96 \pm 11$ \\
$\begin{array}{c}\text { Three-directionally } \\
\text { macrochannelled } \\
\text { calcium phosphate }\end{array}$ & 48 & $278 \pm 14$ & $24 \pm 5$ \\
\hline
\end{tabular}
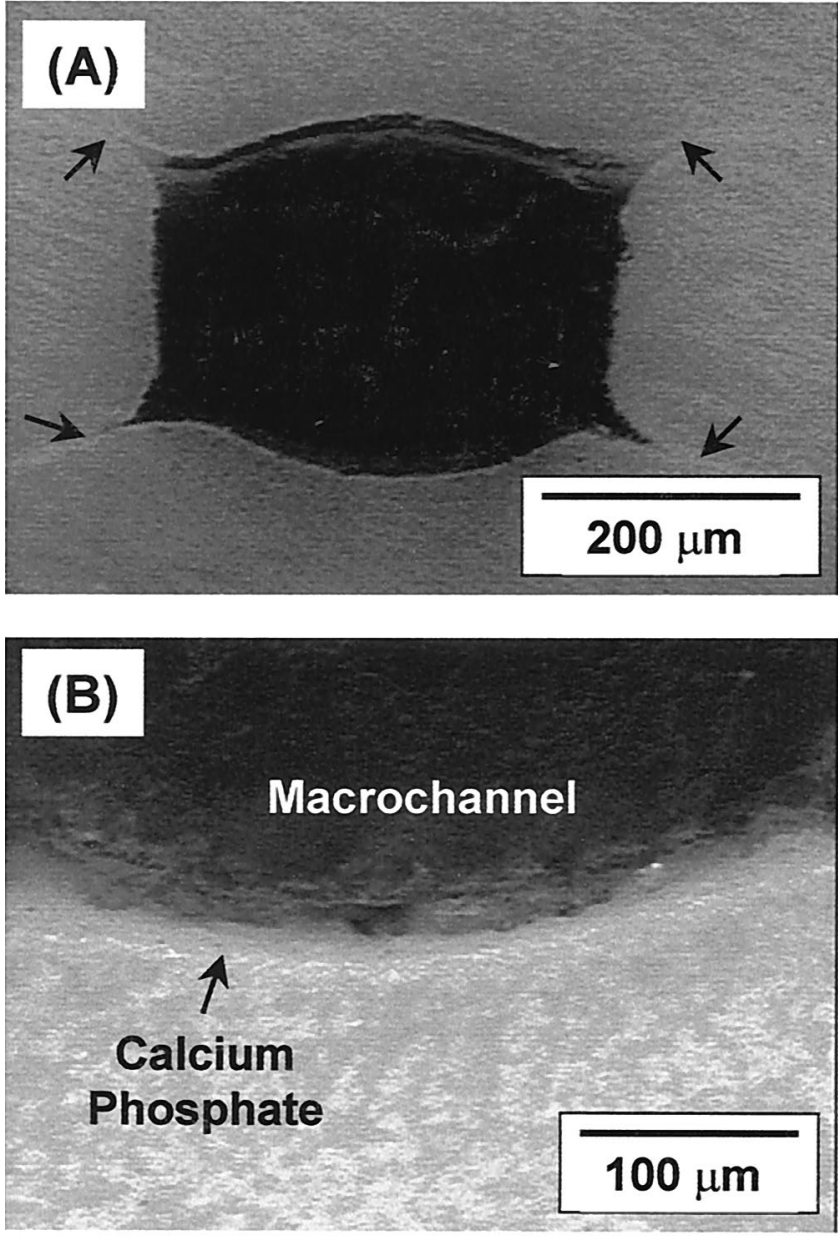

Fig. 5. Optical photographs of a polished surface of the threedirectionally macrochanneled TZP with (A) low and (B) high magnification. Arrows indicate the interfaces of TZP and calcium phosphate.

\section{Summary and Conclusions}

A strong and biocompatible three-directionally macrochanneled TZP-coated bioactive calcium phosphate layer was fabricated using TZP, which was surrounded by a calcium phosphate layer, and carbon black filaments. After sintering, the three-directionally macrochanneled TZP contained $52 \mathrm{vol} \% 290-\mu \mathrm{m}$ pore channels in a uniform array, which were coated on the inside with a calcium phosphate layer. The compressive strength $(96 \pm 11 \mathrm{MPa})$ of the three-directionally macrochanneled TZP was much higher than that $(24 \pm 5 \mathrm{MPa})$ of the three-directionally macrochanneled calcium phosphate. Moreover, excellent biocompatibility is expected due to its bioactive calcium phosphate layer on the bioinert TZP surface.

\section{References}

${ }^{1}$ H. M. Rosen, "Porous, Block HA as an Interpositional Bone Graft Substitute in Orthognatic Surgery," Plast. Reconstr. Surg., 83, 985-90 (1989).

${ }^{2}$ B.-S. Chang, C.-K. Lee, K.-S. Hong, H.-J. Youn, H.-S. Ryu, S.-S. Chung, and K.-W. Park, "Osteoconduction at Porous Hydroxyapatite with Various Pore Configurations," Biomaterials, 21, 1291-98 (2000).

${ }^{3}$ N. Passuti, G. Daculsi, J. M. Rogez, S. Martin, and J. V. Bainvel, "Macroporous Calcium Phosphate Ceramic Performance in Human Spine Fusion," Clin. Orthop. Relat. Res., 248, 169-76 (1989).

${ }^{4}$ K. Satoh and K. Nakatsuka, "Simplified Procedure for Aesthetic Improvement of Facial Contour by Maxillary Augmentation Using a Porous HA Graft for Maxillofacial Deformity," Plast. Reconstr. Surg., 97, 338-44 (1996).

${ }^{5}$ L. L. Hench and J. Wilson, An Introduction to Bioceramics. World Scientific, London, U.K., 1993.

${ }^{6}$ L. L. Hench, "Bioceramics," J. Am. Ceram. Soc., 81 [7] 1705-28 (1998).

${ }^{7}$ R. Z. Legeros, “Apatites in Biological Systems," Prog. Cryst. Growth Charact., 4 $1-45$ (1981). 
${ }^{8}$ C. Lavernia and J. M. Schoenung, "Calcium Phosphate Ceramics as Bone Substitutes," Am. Ceram. Soc. Bull., 70 [1] 95-100 (1991).

${ }^{9}$ D. M. Roy and S. K. Linnehan, "HA Formed from Coral Skeletal Carbonate by Hydrothermal Exchange," Nature (London), 247, 220-22 (1974).

${ }^{10}$ M. Fabbri, G. C. Celotti, and A. Ravaglioli, "Granulates Based on Calcium Phosphate with Controlled Morphology and Porosity for Medical Applications: Physico-Chemical Parameters and Production Technique," Biomaterials, 15, 474-77 (1994).

${ }^{11}$ D. M. Liu, "Fabrication and Characterization of Porous Hydroxyapatite Granules," Biomaterials, 17, 1955-57 (1996).

${ }^{12}$ A. Uchida, S. M. L. Nade, E. R. McCartney, and W. Ching, "The Use of Ceramics for Bone Replacement," J. Bone Jt. Surg., Br. Vol., 66-B, 269-75 (1984).

${ }^{13}$ D. M. Liu, "Control of Pore Geometry on Influencing the Mechanical Property of Porous Hydroxyapatite," J. Mater. Sci. Lett., 15, 419-21 (1996).
${ }^{14}$ D. M. Liu, "Influence of Porosity and Pore Size on the Compressive Strength of Porous Hydroxyapatite Ceramic," Ceram. Int., 23, 135-39 (1997).

${ }^{15}$ J. C. Huec, T. Schaeverbeke, D. Clement, J. Faber, and A. Le Rebeller, "Influence of Porosity on the Mechanical Resistance of Hydroxyapatite Ceramics under Compressive Stress," Biomaterials, 16, 113-18 (1995).

${ }^{16}$ Y.-H. Koh, H.-W. Kim, H.-E. Kim, and J. W. Halloran, "Fabrication of Macrochannelled-Hydroxyapatite Bioceramic by Coextrusion Process," J. Am. Ceram. Soc., 85 [10] 2578-80 (2002).

${ }^{17}$ Y.-H. Koh, H.-W. Kim, H.-E. Kim, and J. W. Halloran, "Fabrication and Compressive Strength of Macrochannelled-Tetragonal Zirconia Polycrystals with Calcium Phosphate Coating Layer," J. Mater. Res., in press.

${ }^{18}$ H.-W. Kim, Y.-H Koh, J.-Y. Noh, and H.-E. Kim, and H.-M. Kim, "Effect of $\mathrm{CaF}_{2}$ on Densification and Properties of Hydroxyapatite-Zirconia Composites for Biomedical Applications," Biomaterials, 23, 4113-21 (2002). 